\title{
Erratum to: An Exploratory Study of Integrative Personality Pathology Systems and the Interpersonal Circumplex
}

\author{
C. J. Hopwood • E. A. Koonce • L. C. Morey
}

Published online: 16 January 2013

(C) Springer Science+Business Media New York 2013

\section{Erratum to: J Psychopathol Behav Assess DOI 10.1007/s10862-008-9124-y}

Calculation errors in "An exploratory study of integrative personality pathology systems and the interpersonal circumplex" by Hopwood, Koonce, and Morey (2009) led to systematic over-estimates of amplitude and elevation parameters reported in that paper. In Table 1 of that paper, amplitude parameters were estimated for two interpersonal surfaces, the Interpersonal Adjective Scales (IAS) and Inventory of Interpersonal Problems Circumplex (IIP-C) using trait scales from the Schedule for Nonadaptive and Adaptive Personality (SNAP) and the Dimensional Assessment of Personality Pathology (DAPP-BQ). As the elevation parameter is of limited interpretability on the IAS, elevation parameters were only reported for the IIP-C.

Correct and reported values for Table 1 of the original paper are reported in Table 1 below. Calculation errors led to reported values that are uniformly higher than actual values (average over-estimate for amplitude was

The online version of the original article can be found at http://dx.doi.org/ 10.1007/s10862-008-9124-y.

C. J. Hopwood $(\bowtie)$

Department of Psychology, Michigan State University, East Lansing, MI 44824-1116, USA

e-mail: hopwood2@msu.edu

\section{E. A. Koonce}

Department of Psychology, University of Toledo, Toledo, $\mathrm{OH}$, USA

L. C. Morey

Department of Psychology, Texas A\&M University, College Station, TX, USA
.13 and the average over-estimate for elevation was .09 ), however the correlations between the reported and correct values were $>.95$ for amplitude across all four subsets of analyses (i.e., IAS and IIP-C with SNAP and DAPP) and the correlations between reported and correct elevations were .86 for the DAPP and IIP-C and .99 for the SNAP and IIP-C. Given that calculation errors were uniform (i.e. largely correct in terms of rank order but consistently higher in terms of magnitude), substantive conclusions from the paper generally hold with the application of a more relaxed rubric for interpreting meaningful elevation and amplitude values. Specifically, Hopwood et al. classified elevation values $>.30$ as indicating meaningful relations to interpersonal problems and amplitude values $>.30$ as indicating thematic interpretability on the interpersonal circumplex surfaces. As all amplitude and elevation parameters that were reported to be $>.30$ are nearly all $>.20$, changing these cutoffs to .20 would lead to the same substantive conclusions. There were two exceptions. First, whereas the DAPP-BQ submissiveness amplitude on the IIP-C was originally reported as .34 , which is above the interpretability cutoff of .30 , the actual value is .18 , which is below the corrected cutoff of .20. Second, the Insecure Attachment amplitude originally reported as .28 was below the cutoff of .30 . However, the actual value of .20 would meet the .20 cutoff for the corrected values. Calculation errors also affected the amplitude estimates reported in the final column of Table 3 of the Hopwood et al. paper. The correct and reported values are given in Table 2. Again, these parameters were uniformly overestimated, and the results do not change substantive conclusions in the paper. 
Table 1 Correct and Reported Amplitude and Elevation Values for Hopwood et al. (2009) Table 1

\begin{tabular}{|c|c|c|c|c|c|c|}
\hline \multirow[b]{2}{*}{ Trait Scale } & \multicolumn{4}{|l|}{ IIP-C } & \multicolumn{2}{|l|}{ IAS } \\
\hline & $\begin{array}{l}\text { Correct } \\
\text { Elevation }\end{array}$ & $\begin{array}{l}\text { Reported } \\
\text { Elevation }\end{array}$ & $\begin{array}{l}\text { Correct } \\
\text { Amplitude }\end{array}$ & $\begin{array}{l}\text { Reported } \\
\text { Amplitude }\end{array}$ & $\begin{array}{l}\text { Correct } \\
\text { Amplitude }\end{array}$ & $\begin{array}{l}\text { Reported } \\
\text { Amplitude }\end{array}$ \\
\hline \multicolumn{7}{|l|}{ SNAP } \\
\hline Impulsivity & -.09 & -.12 & .14 & .24 & .30 & .43 \\
\hline Propriety & .11 & .15 & .04 & .08 & .12 & .11 \\
\hline Workaholism & .13 & .17 & .08 & .15 & .12 & .17 \\
\hline Manipulativeness & .08 & .09 & .15 & .28 & .34 & .54 \\
\hline Mistrust & .25 & .41 & .12 & .26 & .29 & .45 \\
\hline Eccentric Perceptions & .13 & .20 & .05 & .11 & .09 & .13 \\
\hline Aggression & .06 & .06 & .27 & .52 & .33 & .52 \\
\hline Self-Harm & .12 & .21 & .11 & .24 & .32 & .48 \\
\hline Detachment & .25 & .40 & .23 & .48 & .55 & .75 \\
\hline Exhibitionism & -.09 & -.13 & .22 & .37 & .42 & .52 \\
\hline Entitlement & .01 & .02 & .13 & .28 & .31 & .42 \\
\hline Dependency & .20 & .33 & .19 & .33 & .35 & .66 \\
\hline Positive Temperament & -.01 & -.02 & .15 & .29 & .45 & .63 \\
\hline Negative Temperament & .22 & .34 & .07 & .15 & .29 & .41 \\
\hline Disinhibition & -.01 & -.01 & .16 & .26 & .38 & .55 \\
\hline \multicolumn{7}{|l|}{ DAPP-BQ } \\
\hline Submissiveness & .34 & .53 & .18 & .34 & .37 & .50 \\
\hline Cognitive Dysregulation & .33 & .48 & .10 & .20 & .24 & .33 \\
\hline Identity Problems & .36 & .55 & .25 & .47 & .45 & .55 \\
\hline Affective Instability & .34 & .51 & .15 & .28 & .31 & .42 \\
\hline Stimulus Seeking & .09 & .13 & .10 & .17 & .26 & .32 \\
\hline Compulsivity & -.03 & -.07 & .08 & .14 & .15 & .16 \\
\hline Restricted Expression & .27 & .41 & .32 & .56 & .42 & .51 \\
\hline Callousness & .22 & .32 & .38 & .67 & .56 & .65 \\
\hline Oppositionality & .38 & .60 & .05 & .09 & .29 & .36 \\
\hline Intimacy Problems & .12 & .16 & .22 & .34 & .31 & .38 \\
\hline Rejection & .13 & .16 & .33 & .63 & .45 & .53 \\
\hline Anxiety & .34 & .53 & .02 & .04 & .30 & .42 \\
\hline Conduct Problems & .23 & .32 & .28 & .49 & .45 & .53 \\
\hline Suspiciousness & .25 & .66 & .30 & .56 & .42 & .49 \\
\hline Social Avoidance & .43 & .36 & .22 & .37 & .51 & .64 \\
\hline Narcissism & .21 & .34 & .16 & .29 & .10 & .11 \\
\hline Insecure Attachment & .23 & .34 & .04 & .06 & .20 & .28 \\
\hline Self-Harm & .10 & .14 & .15 & .28 & .26 & .34 \\
\hline
\end{tabular}


Table 2 Correct and Reported Amplitude Values for Hopwood et al. (2009) Table 3

\begin{tabular}{lcc}
\hline Trait Scale & Correct Amplitude & Reported Amplitude \\
\hline SNAP & .36 & \\
Exhibitionism & .28 & .55 \\
Disinhibition & .26 & .42 \\
Manipulativeness & .47 & .44 \\
Detachment & & .77 \\
DAPP-BQ & .44 & \\
Rejection & .38 & .64 \\
Callousness & .39 & .68 \\
Suspiciousness & .38 & .56 \\
Conduct Problems & .30 & .54 \\
Intimacy Problems & .42 & .41 \\
Restricted Expression & .41 & .60 \\
Social Avoidance & .19 & .59 \\
Anxiety & .31 & .31 \\
Submissiveness & & .49 \\
\hline
\end{tabular}

